\title{
Lucio Agra*
}

\section{Nos tempos da "guerrilha artística"- ou 0 antigo atentado à horrenda estátua de Borba Gato ${ }^{1}$}

Lucio Agra é professor, ensaísta, pesquisador, artista. Doutor em Comunicação e Semiótica pela PUC SP é professor da UFRB (Universidade Federal do Recôncavo da Bahia), no Cecult (Centro de Cultura, Linguagens e Tecnologias Aplicadas). Atua na performance, com ramificações na música, no teatro, na poesia e nas artes visuais. Cocurador de vários dos Festivais Perfor (2010-2017) em São Paulo, à frente da BrP (Associação Brasil Performance), além de outras curadorias em exposições no Brasil e no exterior. Participou de Festivais em diversos estados brasileiros e em outros países. Tem artigos publicados em revistas e livros (coletâneas) e quatro livros publicados, sendo o mais recente "Décio Pignatari - a vida em noosfera" para a Coleção Sapientia da Educ (Editora da PUC SP, 2018). https://www.youtube. com/c/LucioAgra-arteaovivo lucioagra@ufrb.edu.br ORCID 0000-0002-7725-9833
Resumo Em um dos momentos de urgência da Cultura Brasileira, nos anos 60, a pressão dos acontecimentos fez alguns artistas desenvolverem uma postura "anti-arte" que gerou uma série de produtos ainda pouco analisados na historiografia recente. Esse texto volta-se para experimentos praticamente desconhecidos, em grande parte pela ausência de documentação sobre os mesmos. O M.A.R.D.A., criado por Rogério Duprat e Décio Pignatari, a "Teoria da Guerrilha Artística" e o "Produssumo" (conceito e texto de Pignatari) e os Happenings parecem ter produzido um caldo de cultura de combate que é verdadeiramente estimulante. Conhecemos o que disso resultou, mas pouco sabemos ainda de sua elaboração.

Palavras Chave Produssumo, M.A.R.D.A., Guerrilha Artística, Décio Pignatari, Rogério Duprat. 


\section{In the times of the "artistic guerrilla" - or the ancient attack on the horrific statue of Borba Gato}

Abstract In one of the urgent moments of Brazilian Culture, through the 60s, the pressure of events compelled some artists to develop an "anti-art" position that generated a series of products that still deserve analysis in recent historiography. This text focuses on barely unknown experiments, largely due to the absence of documentation about them. The M.A.R.D.A., movement created by Rogério Duprat and Décio Pignatari, the "Artistic Guerrilla Theory" and the "Produssumo" (Pignatari's concept and text) as well as the advent of Happenings seem to have produced a combat culture ambience that is truly stimulating. We know what resulted from this, but we still know little about its elaboration.

Keywords Produssumo, M.A.R.D.A., artistic guerrilla, Pignatari, Duprat.

\section{En tiempos de la "guerrilla artística" - o el viejo ataque a la espantosa estatua de Borba Gato}

Resumen En uno de los momentos urgentes de la cultura brasileña, en los años 60, la presión de los acontecimientos hizo que algunos artistas desarrollaran una postura "anti-arte" que generó una serie de productos que aún han sido poco analizados en la historiografía reciente. Este texto se centra en experimentos prácticamente desconocidos, en gran parte debido a la ausencia de documentación sobre ellos. El M.A.R.D.A., creado por Rogério Duprat y Décio Pignatari, la "Teoría de la Guerrilla Artística" y el "Produssumo" (concepto y texto de Pignatari) y los Happenings parecen haber producido un caldo de cultura de combate realmente estimulante. Sabemos qué resultó de esto, pero aún sabemos poco sobre su elaboración.

Palabras clave Produssumo, M.A.R.D.A., guerrilla artistica, Pignatari, Duprat. 


\section{prólogo}

Em 2010, numa publicação do SPA das Artes, evento pernambucano surgido a partir de ocupações de artistas em regiões abandonadas da cidade nas décadas anteriores, Fabiana Moraes escreveu:

\footnotetext{
"Em definitivo vivemos o final da era da autonomia na arte, essa herança da Modernidade; é condição para a arte hoje, fazer participar, reunir confrontar, partilhar, aquilo que outrora 'não era arte' (MORAES, 2010)
}

O texto se chama "Lugares de invenção, lugares de resistência" e começa expondo a memória saudosa da autora dos tempos que viveu em Paris e conheceu os squats. No curso de sua argumentação, vai apresentando os problemas decorrentes da progressiva institucionalização dessas mesmas ocupações, que enfrentaram severa resistência, segundo conta, até o ano 2000. Demonstra como o fenômeno se deu em outras capitais da Europa e busca uma analogia com a Recife dos anos 90.

Várias coisas chamam a atenção nesse pequeno trecho-citação. Confrontar e partilhar o que "não é arte" - sabemos - depende muito de pensarmos o que seria entendido como "sendo" arte. Sob outro aspecto, seria interessante indagar em que medida as motivações de artistas franceses - na sua maioria imigrantes, mas também os excluídos de sempre do sistema das artes - teriam sido as mesmas que culminaram com o SPA das artes no Brasil, em Recife. A julgar pelos demais depoimentos, na mesma publicação, os principais motores dos pernambucanos eram dois: questionar a hegemonia vigente no sistema da arte e também apontar para a situação periférica de artistas nordestinos em relação ao Sudeste.

A questão política me atrai bastante nesse debate, mas gostaria de deslocar o foco para outra, também política: a ideia de fim da autonomia da arte. "Autonomia" de linguagem, durante um tempo, foi o que sustentou a possibilidade da experimentação, fazendo com que o Modernismo se livrasse daquilo que, já em fins do século passado, era questionado, a subserviência à "realidade". Dito de outra forma: a crença na arte como representação passiva do real, até pelo menos o século dezenove, obscurecia o possível entendimento dos códigos visuais, sonoros etc que impunham, na verdade, o peculiar modo de fazer essa representação. Grande debate da arte ocidental, de modo geral, essa oposição entre autonomia da linguagem e submissão à realidade é praticamente infindável.

A liberdade de poder instituir um "real do reflexo" - para usar uma célebre paráfrase da exigência do realismo socialista - foi algo caro aos artistas experimentais da primeira metade do século, achacados pela acusação de "formalismo", essa pecha que, infelizmente, ressurge de tempos em tempos.

A autonomia foi, portanto, uma bandeira da arte, ao menos das experimentais. Mas na segunda metade dos anos 60, tudo mudou. 
No último capítulo de "Arte e Mídia" (2007) Arlindo Machado descreve um novo panorama:

Entre os anos 1950 e meados dos 1980, há uma tendência maior de se pensar os meios em função de suas especificidades. (...) Marshall McLuhan é o primeiro a anotar a principal diferença introduzida pela imagem eletrônica: sua natureza "mosaicada", resultado de sua constituição através de linhas de varredura, que lhe determina condições de definição e profundidade de campo completamente diferentes do cinema, além de modos de recepção também distintos.(...) no campo da comunicação, chega um momento em que a divergência entre os meios torna-se improdutiva, limitativa e beligerante, deixando claro, pelo menos aos setores de vanguarda, que a melhor alternativa pode estar na convergência. (MACHADO, 2007: 60/64)

Esse é o princípio, salvo engano, tomado por Dick Higgins no seu manifesto Intermídia de 1966, embora propondo a questão de outra forma. Há, nesse caso, outras implicações:

“...devido à propagação da alfabetização de massa, graças à televisão e ao rádio transistorizado, as nossas sensibilidades mudaram. A própria complexidade desse impacto nos dá um gosto pela simplicidade, por uma arte que está baseada nas imagens subjacentes que um artista sempre usou para chegar ao seu intento. Assim como no caso dos cubistas, estamos buscando um novo modo de olhar para as coisas, só que mais completamente, uma vez que estamos mais impacientes e mais ansiosos para chegar às imagens básicas. Isso explica o impacto dos happenings, peças-evento mixed-media."(HIGGINS [1966]2006:139/140)

E acrescenta, fazendo menção ao caráter "militante" da arte:

"Não pedimos mais que se fale magnificamente em pegar em armas contra um mar de problemas, queremos ver isso feito. A arte que faz isso de modo mais direto é aquela que nos permite essa imediaticidade, com o mínimo de distrações". (HIGGINS [1966]2006:139/140)

Para que essa "arte direta" - com a presença corporal do artista, nas palavras de Higgins, "intensificasse uma tendência que já existia" os artistas "desmoronaram as mídias tradicionais" até um ponto em que funcionavam como meros "pontos de referência", tão arbitrários que só serviam para saber se "tal ou qual trabalho é basicamente musical" quando também é poesia, por exemplo. Essa seria a "abordagem da intermídia", como ele diz, e acrescenta; "Um compositor é um homem morto a não ser que componha para todas as mídias e para o seu mundo" (IDEM) Para juntar as pontas, o que Higgins via como revolucionário era contrapor essa "intermídia", esse conhecimento estético e artístico, à avalanche multimídia que os meios 
oficiais sempre despejavam. Em vez de só falar sobre o Vietnã, "comunicar - dizer o que tem de ser dito à luz de nossos novos meios."

o que mais me encanta nessa proposta é oferecer a possibilidade de que o "tratamento direto da coisa", como dizia Ezra Pound, fosse feito a partir de um engajamento com os meios de seu tempo (outra das observações de Arlindo Machado). O salto crítico aí não é mais pela liberdade em relação ao real, mas se dá a partir da nova relação e consciência dos meios de produção desse real.

\section{anti-arte}

No ano da "Declaração" de Higgins, no Brasil, assunto parecido chegou às páginas da mídia brasileira, em matérias das Revistas Manchete e, dois anos depois, n'O Cruzeiro. A repórter Marisa Alvarez Lima levou 3 meses, segundo ela mesma, para preparar a reportagem de 68 , cujo título seria "Marginália - Arte e cultura na 'idade da pedrada" e que acabou virando o nome do livro-referência de uma época inteira. Publicado pela Editora Salamandra do Rio, em 1996 (1a ed.), ali Marisa reúne os vários artigos que, durante os anos 60 , produziu para as revistas A cigarra e 0 cruzeiro, o que faz com que a coletânea se torne um documento precioso da época. Voltaremos a 1966 mais adiante.

"Marginália..." saiu na véspera da imposição do AI-5. Sua pergunta-chave era: o que ainda seria "o novo"? Ou seja, remetendo ao começo do que aqui escrevo, o que haveria sobrado daquele momento da Modernidade que, se sentia, estava indo para o brejo? "O novo hoje pode estar morto amanhã" sentencia a primeira frase da reportagem. E, em seguida, dá a chave: "Comunicar através da polêmica" Era uma época de debates fortes em que a "rebelião não tem um mero caráter formalista, ela assume seus verdadeiros desígnios, rompendo de vez com as estruturas." Acrescenta, ainda:

\footnotetext{
"Na idade da massa preconiza-se o fim da especialização: Arte \& Cultura passam a ser uma totalidade. Surge então, um conceito verdadeiramente revolucionário: em cada homem existe, em maior ou menor potencialidade, o artista. E a cultura é feita, principalmente, de baixo para cima" (ALVAREZ LIMA, 1996:99/115)
}

A arte em transe, ela diz, como a Terra de um dos depoentes de sua matéria, o cineasta Glauber Rocha. "Não se trata mais de um movimento que se prenda a uma designação, 'Tropicalismo' ou qualquer outro rótulo vanguardista.Trata-se de uma súbita tomada de consciência da realidade brasileira" (ALVAREZ LIMA, 1996:110)

Um outro artigo, publicado em jornal diário, sintetizou isso de forma ainda mais incisiva. As falas de todos os entrevistados por Marisa, reverberam ideias que estão nesse texto: "Teoria da Guerrilha Artística" de Décio Pignatari (Correio da Manhã, 4 de junho de 1967, republicado em PIGNATARI, 1971:157), de algum modo aclimatou Higgins para os fins do momento. 
Vamos aos fragmentos das falas dos entrevistados por Marisa A. Lima. Como disse, a pergunta- chave da reportagem que ela fez em 68, era sobre o que ainda seria o novo. Naquele momento parece que era possível perceber o que não funcionava mais: o discurso sobre o específico de cada linguagem. Sentia-se uma urgência, havia uma espécie de voracidade no ar. A perplexidade manifesta entre as pessoas entrevistadas, diz um pouco a respeito disso: elas respondiam principalmente através daquilo que é o mote da própria reportagem: a "idade da pedrada" era uma expressão criada por Oswald de Andrade que dizia não vivermos mais na idade da pedra, claro, mas na idade da pedrada. Referia-se à atitude dos estudantes da Faculdade de Direito do Largo de São Francisco, por ocasião do empastelamento do jornal O Homem do Povo, no começo dos anos de 1930. Independentemente da diferença de contexto, a expressão cabia muito bem naquele momento $67 / 68$.

Quando Dick Higgins aponta essa simultaneidade, o desenvolvimento da interligação entre meios e linguagens, isso carrega a dimensão política que se passa cabalmente na sociedade. As pessoas vão à rua em grande medida também para dar conta dessa multiplicidade simultânea de acontecimentos. No Brasil, nos Estados Unidos e na Europa, para não falar no restante do mundo, há uma intensa movimentação e as manifestações públicas refletem isso. A resposta que os artistas que Marisa Alvarez Lima elenca e entrevista reflete esse espírito: a arte acabou, a arte não faz mais nenhum sentido, seria necessário partir para a ação, para a antiarte. A marginalidade adquire sinal positivo, tanto é que o estandarte, a faixa, a proclamação, com sua urgência, tornam-se interessantes. "Seja marginal seja herói" de Hélio Oiticica, a bandeira "Canalha" de Waldemar Cordeiro e as sugestões de faixas de Décio Pignatari vão comparecer nas passeatas. No depoimento de Rogério Duarte, por exemplo. Seu início já anuncia:

\footnotetext{
"Eu odeio o novo /isso é duvidoso /Sartre me incluiria na direita /e talvez o poder perdoasse a existência da minha fome /Eu odeio o novo /Repetirei até o final /Que odeio o novo /Não porque é duvidoso /Porque eu amo /Que esta certeza /Te chegue duvidosa /Precária como toda a riqueza." (ALVAREZ LIMA, 1996:102)
}

Assim ele vai construindo um texto formado inteiramente de contradições. Seria preciso lembrar que Rogério Duarte e seu irmão foram presos de forma completamente arbitrária na saída da missa de sétimo dia da morte do estudante Edson Luís, baleado em uma outra "passeata". Também a opinião de Haroldo de Campos é referida na reportagem

\footnotetext{
“Costuma-se falar que a poesia de hoje, especialmente de Vanguarda, está num beco sem saída. Se por beco sem saída se entende algo como situação limite, parece-me que toda arte contemporânea consciente de si mesma enfrenta necessariamente este problema."
} 
E conclui dizendo: "a cada lance de dados relançados contra o acaso, raros (porém novos) poemas-beco-sem-saída” (ALVAREZ LIMA, Idem, grifos do autor). Mesmo Haroldo de Campos, defende o beco sem saída.

Ítala Nandi, atriz de destaque, do elenco do Teatro Oficina: "Eu poderia não estar mais escrevendo [sic] nada. Mas aqui estou. No entanto para me consolar, digo sempre: mea culpa, mea culpa." Caetano Veloso cita um poema de Pasolini sobre a rebelião estudantil ("um antipoema") e Gilberto Gil diz que

“outro dia comentava com Caetano e Uali, um amigo da Bahia [Wally Salomão, ainda desconhecido naquela altura] a respeito da minha dúvida com relação às possíveis saídas. Então Caetano disse que talvez a única coisa que nos sirva agora como instrumento de reflexão a respeito seja o pensamento de McLuhan: 'O meio é a mensagem' A partir daí eu diria que a arte fora da lei, a antiarte ou a superarte são, para a arte, a única posição em que este pensamento de máquina pode ser assumido com uma certa tranquilidade." (ALVAREZ LIMA, 1996:103)

O depoimento de Torquato Neto já começa dizendo: "Só acredito no artista fora da lei". O depoimento do Capinan diz: "Diante de tudo e de si mesma a Arte tem que estar fora da lei". O humorista Jaguar diz: "A barra tá pesada para nós humoristas". José Agrippino de Paula diz: "Todo autor do terceiro mundo é maldito". Hélio Pelegrino diz: "O mundo tal como está não presta né?". Franklin Martins - que iria em breve escorregar para a clandestinidade, logo em seguida, diz: "A cultura reflete uma visão de classe. A cultura, na sociedade atual, é, portanto, uma cultura que visa adormecer o povo." Zé Celso Martinez Correia diz, recém saído de sofrer o ataque do CCC: "Hoje somos bandidos finalmente atacados pela Sagrada SS-CC, pela eficiência suíça da censura federal - hoje estamos nós sem família, sem tradição e sem propriedade, talvez muito mais próximos da Verdade do Gigante explorado também sem tradição, sem família e sem propriedade. Décio Pignatari afirma:

"A colagem é a sintaxe provisória da síntese criativa, sintaxe de massa.A colagem é a montagem da simultaneidade, totem geral. É tempo de massa e de síntese e não de centralização. Não há mais tempo para textos só para títulos. Textítulos. Só a NOVA BARBÁRIE [sic] abre a sensibilidade aos contatos vivos."

Voltarei a essa passagem adiante. "Mallarmé, 'no exílio do exílio, à margem da margem" diz Augusto de Campos e prossegue:

“... já dizia que o poeta está EM GREVE perante a sociedade. O estado de greve é o estado de graça do artista, outlaw meio jogral, meio louco, meio gênio, que brinca sempre a sério. Essa legalidade, que leva muitas vezes ao marginalismo, é alienação apenas na aparência. Na verdade, é uma participação pelo avesso" (ALVAREZ LIMA, 1996:106/107) 
Adiante, Glauber Rocha não tem mais "nenhum ponto de vista sobre o que deve ser a arte no Brasil e no resto do mundo". Rogério Sganzerla: “A meu ver não há nenhum motivo de surpresa se o artista moderno for chamado de Fora da Lei. Orson Welles, Maiakovski, Lorca ou Vigo, todos eles esgotaram o tradicional romantismo inerente à condição do artista maldito". Renato Borghi: "O mundo explode! Racha!" Ferreira Gullar declara: "Em nossos dias, torna-se mais claro que nunca o compromisso da arte com o presente." No meio disso aparece um certo Padre João Batista:"Até há pouco as manifestações de protesto eram patrimônio de países subdesenvolvidos. Hoje as vemos também nos países desenvolvidos." Mário Schenberg; "A arte reflete os anseios mais significativos do homem em cada um momento histórico." Há ainda depoimentos de Pedro Escosteguy, Antonio Henrique Amaral, enfim é, portanto, o diagnóstico da época, um diagnóstico de choque.

Dos resultados disso tudo sabemos nós. A própria Marisa descreve em texto-memória no livro, lembrando que o estandarte de Che-Guevara de Antonio Henrique Amaral, que ela fotografou na mão de Hélio Oiticica, (reproduzido no livro de 1996), desapareceu misteriosamente de sua casa naquele mesmo 1968. As imagens que ilustram a reportagem refletem uma estética pop (como no caso da de Décio Pignatari) ou algo que oscila entre fantasias do Chacrinha ou outras enigmáticas figuras como a do cineasta baiano Fernando Cony Campos na estátua do Borba Gato ou um grupo que inclui José Agrippino de Paula, Jô Soares (que atuaria em Hitler no 3o Mundo, de Agrippino) e Torquato Neto em um encontro improvável diante de um avião de combate em exposição no Campo de Marte; Zé Celso posa em cima de uma pedra e Hélio Oiticica, de ponta cabeça numa árvore, segura o malsinado estandarte do Che. Zé do Caixão e seus asseclas, cercados de imagens de lojas de Umbanda, os Mutantes junto a uma Banana esculpida por Antonio Henrique Amaral. Claudio Tozzi amarrado sobre o teto de um fusca. Aparentemente a (falta de) lógica da colagem só almeja produzir o efeito de surpresa que uma reportagem desse tipo poderia ter em uma revista popular de atualidades em grande circulação, como 0 Cruzeiro.

Fig 1. Fernando Campos e o Borba Gato, foto de Ronaldo Câmara e Geraldo Viola

Fonte Marginália - ALVAREZ LIMA, 1996 Reprodução anti-monumento

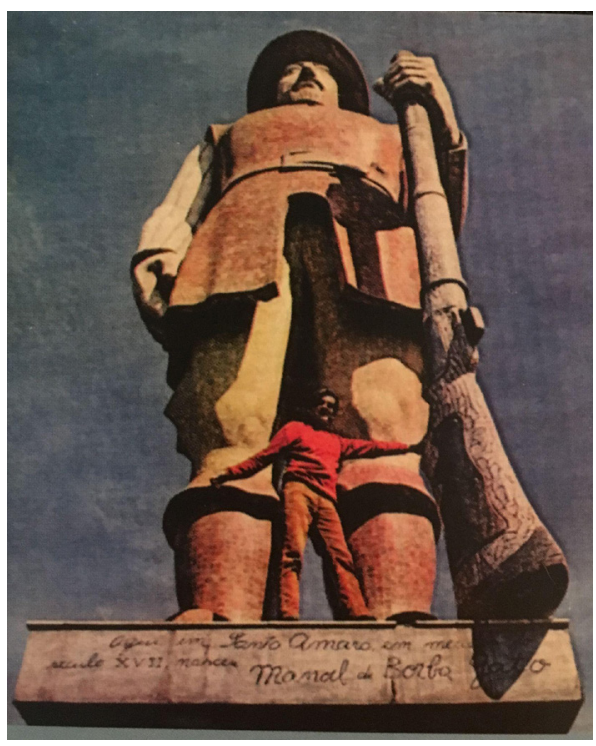

DATJournal v.6 n.3 2021 
Quem acabou de ler a passagem acima e está minimamente ligado nos acontecimentos atuais lembrará que a estátua de Borba Gato voltou a povoar as manchetes recentemente, por ter sido "atacada" por um incêndio. Na verdade esse é mais um dos acontecimentos que essa infeliz "escultura" vem protagonizando ao longo dos tempos. Por volta de 1965/66, um grupo de artistas retornava de uma frustrada experiência de construção de uma nova proposta pedagógica e artística: a UnB. Nesse momento só nos interessa falar de dois desses artistas em especial: Rogério Duprat e Décio Pignatari. Isso porque, malgrado não terem sido os únicos entre mais de 200 professores signatários de um pedido coletivo de demissão em função de cassações na Universidade entre 64 e 65 , serão os dois que iniciarão um movimento muito ao estilo "anti-arte" que a reportagem de Marisa Alvarez, anos mais tarde, irá registrar. Trata-se do M.A.R.D.A., o Movimento de Arregimentação Radical em Defesa da Arte, uma brincadeira "séria" que terá influência marcante, embora não percebida ainda hoje, no que depois ficou conhecido como "Tropicalismo". A estátua de Borba Gato, o Cemitério da Consolação (de onde foram expulsos) e até a criação de uma fotonovela, posteriormente publicada no livro Contracomunicação (1a edição, 1971), são alguns dos feitos do M.A.R.D.A., um movimento que eleva ao status de grande obra de arte tudo que havia de mais desprezível na cultura de massa. Conforme o depoimento que ambos, Duprat e Pignatari, dão no documentário de Pedro Vieira, o qual citaremos aqui algumas vezes ${ }^{2}$, tratava-se de produzir um movimento de esculacho, de esculhambação, porque àquela altura a arte de "alto repertório" (Pignatari) torna-se progressivamente impossível. Ao mesmo tempo, esquenta o debate em torno de um conjunto de novas ideias que se relacionam com isso: o kitsch (graças à publicação, no Brasil, do livro de Abraham Moles a respeito), o Happening (de que falaremos a seguir), o pop-rock que deságua no contraparte brasileira do "iê-iê-iê" (muito explorado comercialmente) e a Tropicália. Entre 65 e 68 os rumos da cultura, da mídia, do entretenimento e de tudo mais se alteram rápida e radicalmente, anunciando um provável período de extremos que recebe, repentinamente, em Dezembro de 1968, o baque da edição do AI-5.

Fig 2. Frame de "Vida de Músico" de Pedro Vieira. Duprat e Pignatari conversam tendo a estátua de Borba Gato atrás, na época de produção do documentário (fins dos anos 90) Fonte Pedro Vieira

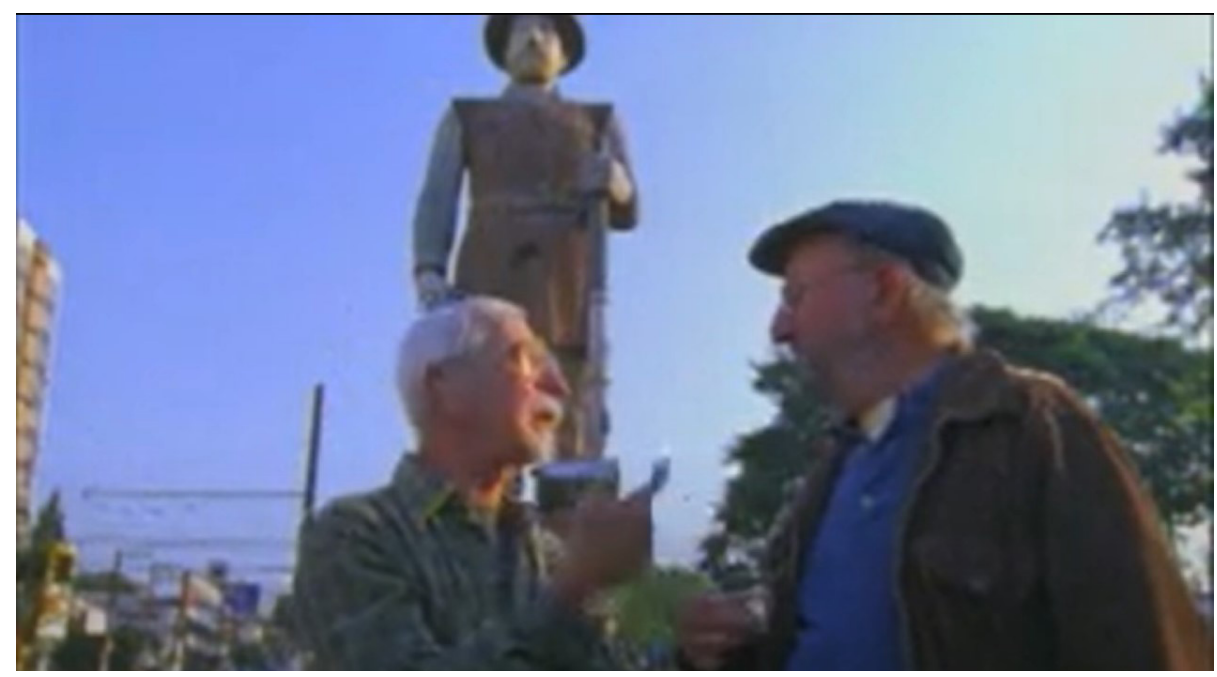




\section{happenings nos bares e na TV}

"Produssumo": Seria o amigo dileto de Duprat, Décio Pignatari, em texto publicado na Folha de São Paulo de 11 de maio de 1966, que sugeria uma interpretação mais específica do happening, no momento em que revia a sua própria atuação - e a de seus companheiros ligados ao Música Nova - em happenings realizados na cidade de São Paulo. Assim Décio os define:

\footnotetext{
"O happening é uma criação da pop art americana. O significado que possa ter deriva do fato de ser uma manifestação 'antiarte', reatando a posição crítica de Dada (a partir de 1915). No entanto, e justamente por isto, trata-se de uma manifestação 'artística' naquilo que tem de artesanal, de não-reprodutibilidade e de público restrito. (...) o happening já demonstra tendências à institucionalização (como novo gênero de espetáculo). A rigor, se isto ocorrer, deixará de ser happening." (PIGNATARI, 1971: 233) 35
}

O texto de Décio é um primeiro resumo dos procedimentos (artesanal, não reproduzível, público restrito) do happening. A provável estreia do Happening em São Paulo deve parte de seu "acontecimento" ao empenho do irmão de Sandino Hohagen, um dos compositores integrantes do grupo Música Nova. Ao menos é o que Lafayette Hohagen narra em seu blog, onde conta a saborosa anedota do evento que movimentou o "Juão Sebastião Bar":

"E foi ali, naquele templo da Bossa Nova paulista, que participei da produção do mais inusitado espetáculo de minha vida. Um 'happening'. o 'happening' era uma manifestação artística tendo como base música aleatória e poesia concreta, que reunia artistas de diversos segmentos em uma performance criada na hora, sem roteiros nem scripts. Já tinha assistido algo parecido, mas na rua, quando morei em New York. Propus ao amigo Blota Neto, novo dono do Juão, que queria dar um "up" na casa, fazer algo diferente e ele topou. Falei com meu irmão, o maestro Sandino Hohagen, que gostou da ideia e junto com seus colegas, também maestros, Rogério Duprat, Damiano Cozzella e o poeta Décio Pignatari, comandaram a maior loucura que lá se viu. Vários alunos de música do Rogério e do Cozzella foram convidados e se integraram ao quarteto. Décio lia suas poesias concretas, uma vitrola tocava hinos patrióticos, Sandino regia a nona sinfonia de Beethoven apenas lendo a partitura, sem música... O público começou a se entusiasmar e a interagir. De repente, vai ao palco um rapaz fazendo um discurso inflamado em alemão; Rogério Duprat com um penico na mão fazia coleta de doações e depois jogava as moedas para o público. (...) Na parede de fundo do palco, um imenso outdoor da propaganda do famoso xarope São João, com a célebre frase do sujeito ameaçado de mordaça: 'Largue-me. Deixe-me gritar'. ${ }^{3}$ 
O episódio é narrado mais ou menos com as mesmas cores pelo próprio Décio, juntamente com Duprat, no documentário de Pedro Vieira, que captura uma conversa entre eles. Pignatari, no seu típico tom incisivo, afirma: "Fomos nós! Fomos nós que fizemos o primeiro happening"! (ver nota 2)

O Juão Sebastião Bar foi, como o próprio texto assinala, um dos "templos da bossa nova" paulista, fazendo parte de um conjunto de casas noturnas que, desde fins dos anos 50, se reunia em torno da Rua Major Sertório, no centro da capital paulista.Pode-se encontrar um mapa detalhado dessa geografia musical no livro de Ruy Castro, Chega de Saudade, como encarte entre as páginas 240 e 241.

\section{antiarte: M.A.R.D.A.}

Volto agora a Décio Pignatari para fazer uma espécie de ponte para seu outro artigo de 1967, portanto ainda próximo de Higgins, tanto nas datas quanto no conteúdo. Suponho, sem poder afirmar com certeza, que se trata de um diálogo possível com as ideias do poeta americano que, aliás, era amigo de Augusto de Campos. O pequeno ensaio - publicado em jornal, sintetiza, também, admiravelmente o espírito que paira na reportagem de Marisa Alvarez Lima. Aliás o depoimento que Décio daria àquela reportagem também está no livro que reúne o artigo que menciono e vários outros sob o sintomático título de Contracomunicação (PIGNATARI, 1971), onde aparece numerado como o segundo da primeira parte, na página 27 , constando, no rodapé, da referência "O Cruzeiro, 1969". O erro da data, certamente, faz algum sentido.

O pequeno artigo de 67 chama-se "Teoria da Guerrilha Artística", recolhido na página 157 dessa primeira edição, em um volume que, ilustrado por quadrinhos e manchetes, é um tratado da Semiótica desse momento estético e extremo do Brasil. Um material explícito do M.A.R.D.A. também viria a comparecer no volume, o roteiro da "audiofotonovela" "Desatinos do Destino", estrelada por Rogério Duprat, Damiano Cozzella, Tânia Taterka, o próprio Décio e o narrador, famoso na época, Solano Ribeiro. A primeira apresentação se deu no Teatro Galpão (Ruth Escobar) em 2 de janeiro de 1970, portanto bem depois do ciclo. No documentário de Pedro Vieira citado, algumas fotos, transformadas em slides, são apresentadas. No roteiro reproduzido no livro aparecem colunas denominadas Video e Audio. Muito embora o "video-tape" fosse um aparato ainda não-doméstico, a intenção é clara: emular o texto televisual (PIGNATARI, 1971:75/87)

$\mathrm{Na}$ "Teoria da Guerrilha Artística", Décio principia descrevendo de que modo a aceleração do processo de informação e comunicação vai arrebentando os sistemas lineares e instaurando sistemas de informação instantânea. Se comparado com a argumentação de Higgins, há uma proximidade muito grande. Em seguida Pignatari assinala que os processos lineares dos nexos de causa e efeito são vinculados à lógica aristotélica verbal, tema que viria a ser discutido mais profundamente por Haroldo de Campos no 
famoso volume Ideograma:Lógica Poesia Linguagem, cuja primeira edição é de 1977, muito embora a questão do Ideograma já estivesse nos próprios manifestos iniciais da Poesia Concreta, incluindo o "plano piloto" de 1958. Era um tema corrente no grupo a que me refiro aqui.

Prosseguindo, Pignatari afirma ainda que nos processos constelacionais, ou abertos, onde o que importa são as propriedades da totalidade, como diz Wolfgang Wieser, uma causa e seu efeito podem, para quem olhasse a totalidade, ser tomados um pelo outro como que trocando seus papéis. Por esse caminho ele chega à surpreendente afirmação: "Nada mais parecido com uma constelação que uma Guerrilha" (PIGNATARI, 1971:158)

Mallarmé pega em armas para derrubar o sistema. No final desse parágrafo, a afirmação-corolário é igualmente interessante: "Estruturalmente, a guerrilha já é projeto e prospecto, já é design que tem por desígnio uma nova sociedade" Adiante:

\footnotetext{
"Os nossos filósofos psicólogos e sociólogos ainda não tem informação matemática e científica e sim 'humanística'. No entanto, já nos bancos universitários, aprendem a adotar uma postura 'científica'. Fingem, por exemplo, menosprezar a literatura - mas são literatos.” Seriam, pois, mais anti artistas que os artistas anti arte da reportagem da $\mathrm{O}$ Cruzeiro. "Quando chega a informação nova, sintético-ideogrâmica, ficam paralisados por ela e aí ficam não sabem fazer as perguntas"(...) "Mas eis que de repente lhes surge pela frente um pensador europeu da nova geração - Foucault, por exemplo - que lhes fala com o maior desembaraço de Mallarmé, Joyce, a lei dos "quanta” e a "Teoria da Informação". (PIGNATARI, 1971:159)
}

Décio conclui que "não sabendo o que perguntar tomam notas".

Decerto ele foi motivado também, em grande parte, pelos debates dos quais participou na época, como um famoso encontro com estudantes ao lado de Caetano Veloso ou aquele registrado por Glauber Rocha em Câncer (1968-1972), quase como apresentação do filme, o mesmo no qual aparece uma emblemática cena de personas marginais, com Hélio Oiticica, Rogério Duarte e Antônio Pitanga.

O clima das discussões que Décio movimenta neste texto aponta para as urgências de Terra em Transe (1967) e principalmente, Câncer. Na reportagem de Marisa Alvarez Lima, o outro baiano, o cineasta Fernando Cony Campos (grafado apenas como Fernando Campos) surge como autor de dois filmes que não realizou, um deles intitulado "Tupi or not Tupi". Com a "benção" da recuperação estratégica da Antropofagia de Oswald de Andrade, estava traçado o quadro onde trafegavam, sob o desígnio da Guerrilha Artística, as táticas do "produssumo" (produção + consumo, oswaldianamente), e do avacalho proposto por M.A.R.D.A. que já se misturava ao Tropicalismo e desbordava nos Happenings. Tudo é Vanguarda (produção+consumo $=$ consumo de vanguarda) e todos os guerrilheiros são vanguardeiros (termo usado pelo próprio Décio). 
"A visão de estruturas", a arte e a vida como eventos-obras. Pignatari defende "eventos e estruturas". Naturalmente se vivia na época o boom do estruturalismo. Há ainda aquele encantamento com esse tipo de proposição.

Outro detalhe interessante, ainda sobre "Teoria da Guerrilha Artística", pode estabelecer mais um "link" com o M.A.R.D.A. Como costumava fazer, Décio cita Oswald de Andrade diversas vezes e, em detalhe, refere-se a um amigo em comum, Pompeu de Souza, que teria sido encarregado pelo próprio Oswald da redação final de um outro manifesto, elaborado pelo próprio poeta nos anos 40, do qual nada se sabe: o Manifesto Zumbi, correspondente a um certo "Projeto Zumbi"

\footnotetext{
"pelo qual propunha uma espécie de frente ampla dos artistas modernos, no sentido de organizarem uma resistência sistemática - até o último homem - a todas as tentativas de institucionalização (absorção) da arte moderna. (...) a resposta de Oswald (...) trazia no seu bojo a possibilidade de uma verdadeira 'revolução cultural' “ (PIGNATARI. 1971:161)
}

Nos termos propostos, o artigo vem ao encontro do vocabulário da época mas prossegue:

\footnotetext{
“O 'Projeto Zumbi' se insere no processo geral da vanguarda, deflagrado no século passado [XIX] sob a pressão da revolução industrial, processo esse que vem estabelecendo um desenvolvimento marginal da arte em relação ao sistema artístico estabelecido e em oposição a ele. Sua estrutura dinâmica só é insignificante dentro de uma visada sincrônica e não diacrônica, ou seja simultânea e não cronológica. Mas por ora se alguém conta ninguém canta esse Zumbi. Cantarão porém: A massa ainda comerá do biscoito fino que fabrico (O. de Andrade)" (PIGNATARI. 1971:161)
}

Há aí, obviamente, um trocadilho citacional, fazendo uma referência ao Arena conta Zumbi, que está em cartaz.

O Rei da vela, a peça de Oswald, é montada no Oficina em agosto daquele ano (1967) "para espanto e escarnecimento de todos os lineares teatrais” (PIGNATARI. 1971:162)

O que Décio, portanto, entendia como Guerrilha Artística estava no caminho do que Marisa Alvarez reúne na sua reportagem, o que nos faz pensar que de alguma maneira havia aí uma produção também de um conjunto de ideias que motivavam esse tipo de ação e que eram movidas principalmente pela ideia de antiarte.

o Contracomunicação de Pignatari testemunha também uma transformação substancial no modelo e na função da arte construtivista que vinha sendo até então a marca daquele grupo, sobretudo o grupo concreto em São Paulo. Já havia acontecido a exposição “ popcretos” (Augusto de Campos e Waldemar Cordeiro) onde se emprega a colagem e montagem, a simultaneidade sob o peso do Golpe de 64. Geraldo de Barros fazia traba- 
lhos que se apropriavam de fragmentos de Outdoors, enfim, havia um investimento na novidade pop mas também naquilo que Décio sugere (neste e em outros textos): a ideia de absorção da lógica do consumo, da lógica da sociedade de consumo, defendida tanto por ele como por Rogério Duprat, através de práticas relacionadas ao princípio do Produssumo. Aliás eu diria que Rogério Duprat foi mais radical nessa defesa do que o próprio Décio.

O crítico e historiador Carlos Calado, ao fazer o obituário do Rogério Duprat, diz o seguinte:

\footnotetext{
“Em 63 ao lado de Damiano Cozzella e Júlio Medaglia, entre outros, lançou o Manifesto Música Nova, cuja plataforma propunha uma arte mais participativa e a compreensão do fenômeno artístico como parte da Indústria Cultural" (CALADO, 2006)
}

No mesmo ano do Manifesto da Música Nova, 1963, a atividade de Duprat já compreendia uma proximidade com a Indústria Cultural. Recentemente um querido amigo, Carlos Ávila, me advertiu da existência de um vinil compacto simples lançado pelo selo VS (Vilella Santos Ltda) com o cantor de rock'n'roll Albert Pavão, compreendendo as composições "Vigésimo andar" e "Sobre um rio tão calmo", cujos arranjos e produção são assinados por Duprat ${ }^{4}$. Um outro amigo, Rafael Silva Lemos, me guiou até a edição da Manchete de 13 de agosto de 1966, onde se narra o primeiro happening do grupo, reportagem que começa com Décio afirmando, polêmica e ironicamente: "Oh, como é terrível este momento pop!"

\section{conclusão em aberto: eventos desconhecidos}

Não há biografias escritas sobre Rogério Duprat. Há a videobiografia de 50 minutos, do cineasta Pedro Veira. E dois livros, o de Regiane Gaúna - que é um estudo, mesclado ao intento de biografia e o de Massimo Barro - cujo foco volta-se para as trilhas criadas por Duprat. Nenhum desses materiais menciona uma produção de Duprat no terreno da música pop, bem no começo dos anos $60 .^{5}$

Massimo Barro, volta-se à atividade do criador de trilhas sonoras . Já em 1957, Duprat havia trabalhado na orquestração da trilha para a montagem de "Eles não usam black-tie" para o TBC, com muito sucesso. É de 1963, também, a trilha do filme A Ilha, primeira colaboração com o cineasta Walter Hugo Khouri, uma parceira que se estenderia por muitos anos.

Em 1965, quando Duprat e Pignatari se associam a alguns membros do Música Nova como Damiano Cozzella para criar o MARDA, já haviam acontecido as viagens à Europa,o impacto do "aleatorismo" com a estética de John Cage, o contato com Frank Zappa ${ }^{6}$, e o trágico encerramento do período de Brasília. "Inspirado nos happenings de John Cage, o grupo fazia debochadas 'homenagens' a estátuas e monumentos de mau gosto." 
O próprio Duprat observa, em depoimento, dado para a Revista Brasileira de Música e publicado em 2012, anos depois de sua morte:

\footnotetext{
“Como grupo Música Nova deixamos de existir em 1964: Cozzella, Pignatari, Régis e eu fomos para Brasília. (...) [Quando voltamos a São Paulo] fundamos o MARDA (Movimento de Arregimentação Radical em Defesa da Arte) e prestamos uma série de homenagens a alguns monumentos de São Paulo, proverbialmente chamados de 'mau gosto' - fotografado e publicado na revista Manchete de 13 de agosto de 1966. Portávamos cartazes em defesa do mau gosto e contra qualquer critério de juízo. Porque tudo é arte e nada é arte: o que vale é o significado. A arte acabou (embora muita gente ainda vá viver dela algum tempo, enquanto houver alguns 'compradores de arte"' (DUPRAT, 2012: 215)7
}

Como já disse no início desse artigo, a série de acontecimentos que conecta o Música Nova, a ida para UnB e o retorno repentino a São Paulo, culminou com a demissão de 15 professores da UnB pela pela Ditadura imposta a partir de abril de 1964.

O diagnóstico de Duprat sobre o fim da arte, pleno de ironia, foi levado a sério.

No primeiro happening M.A.R.D.A., o roteiro incluiu visita ao Cemitério da Consolação, no túmulo de um pintor famoso e tradicionalíssimo, para depois rumar para a estátua de Borba Gato. Duprat, na reportagem, a define como "desafio" e diz que ela é o que podemos denominar "a grande comunicação" (ACUIO, 1966:137)

O maestro redirecionou as rotas de sua atividade de compositor, tornando-se grande autor de trilhas e jingles memoráveis. No ambiente do produssumo, viria, rapidamente, a demanda da Tropicália, o principal catalisador dessas posições. 


\section{Notas}

1. Este texto resulta da junção de 3 outros textos, um fragmento inédito e duas partes de outros: um trecho descartado de um texto publicado posteriormente e outro apresentado no Simpósio Intermidialidade, na sessão do dia 27 de novembro de 2020, promovido pelo grupo de pesquisa homônimo coordenado pelo Prof. João Queiroz no Instituto de Artes da UFJF. Desse último, partindo da transcrição de minha exposição oral, concatenei um texto escrito que se articula com as outras passagens.Ao mesmo tempo essa é a versão inédita do último capítulo do livro que encerra um projeto de pesquisa de 3 anos no Cecult da UFRB, onde trabalho hoje em dia. Vai integrar um livro com o título (provisório) de "A síntese imprevista - acaso e projeto na Arte brasileira dos 60 e 70". Agradeço a Carlos Ávila, Pedro Vieira e Rafael Silva Lemos, as preciosas informações que me levaram a esse ponto da pesquisa. 2. Pedro Vieira Rogério Duprat - Oiregor Tarpud Grifa cinematográfica/Teleimage/TV Cultura, 2002; trailer disponível no YouTube: https://www.youtube.com/watch?v=sSebXkwuYZo (acesso em 18/08/2021) (posteriormente exibido como Rogério Duprat - Vida de músico) 3. Pode-se ler 0 texto completo em http://www.saopaulominhacidade.com.br/historia/ ver/4838/Juao\%2BSebastiao \%2BBar/pagina/2 (Acesso em 18/08/2021)

4.0s áudios dessa gravação podem ser ouvidos em https://www.youtube.com/watch?v=QyIE8fT8TiA (acesso em 23 de agosto de 2021)

5.0 livro da musicóloga Regiane Gaúna (2002) tenta esboçar uma biografia mas é principalmente um cuidadoso estudo da obra de Duprat. 0 de Massimo Barro (2009), volta-se principalmente para o trabalho do maestro em trilhas de cinema, uma vez que o próprio Barro foi um grande nome dessa linguagem, montador prestigiado tendo trabalhado na Vera Cruz e na Maristela Filmes

6.Duprat foi colega de Frank Zappa nos seminários europeus (informação dada por Pedro Vieira segundo depoimento feito a ele pelo próprio Rogério Duprat)

7.Não foi possível encontrar o referido artigo de 1966. Uma recente palestra com o pesquisador Rafael Silva Lemos esclareceu as origens dessa reportagem. A referência está correta e é, com certeza, o outro único documento público sobre M.A.R.D.A, além da matéria de Marisa Alvarez Lima. 


\section{Referências}

ACUIO, Carlos "MARDA, a sigla do happening" Manchete 747 Rio, Bloch Editores, $13 / 08 / 1966$

ALVAREZ LIMA, Marisa Marginália: arte e cultura na Idade da Pedrada Rio, Salamandra, 1996

BARRO, Massimo Rogério Duprat - ecletismo musical SP, Imprensa Oficial, 2009 (Coleção Aplauso Música)

CALADO, Carlos "Músico rompeu as fronteiras entre erudito e popular" in Folha de SP Ilustrada, São Paulo, Folha, 27/10/2006

CAMPOS, Augusto de Balanço da Bossa \& outras bossas São Paulo, Perspectiva, 1993

CASTRO, Ruy Chega de Saudade - A história e as histórias da Bossa Nova São Paulo, Cia. das Letras 1990.

DUPRAT, Rogério “pós-pronunciamentos" in Revista Brasileira de música Rio, Programa de pós-graduação em Música, Escola de Música da UFRJ n.1 jan-jun 2012

GAÚNA, Regiane Rogério Duprat: sonoridades múltiplas São Paulo, Ed. Unesp, 2002.

HIGGINS, Dick “Declarações sobre a intermídia” (1966) in COTRIM, Cecilia e FERREIRA, Glória Escritos de Artistas anos 60/70 Rio, Jorge Zahar, 2006

MACHADO, Arlindo, Arte e midia Rio de Janeiro : Jorge Zahar Ed., 2007.

MORAES, Fabiana de "Lugares de invenção, lugares de resistência" in ReviSPA das Artes Recife ‘10 Recife, Prefeitura do Recife / Funarte, 2010, pp. 36-39.

PIGNATARI, Décio Contracomunicação SP, Perspectiva, 1971

PIGNATARI, Décio “Duprat” in Errâncias São Paulo, Ed. Senac, 2000, pp172/175 